\title{
Mudança organizacional e satisfação no trabalho: um estudo com servidores públicos do estado de Minas Gerais
}

\author{
Antônio Luiz Marques \\ Faculdade Novos Horizontes / Curso de Mestrado em Administração \\ Belo Horizonte / MG - Brasil \\ Renata Borges \\ Universidade Federal de Minas Gerais / Departamento de Ciências Administrativas \\ Belo Horizonte / MG - Brasil \\ Isabella do Couto Reis \\ Universidade Federal de Minas Gerais / Centro de Pós-Graduação e Pesquisas em \\ Administração \\ Belo Horizonte / MG - Brasil
}

\begin{abstract}
Um dos fatores importantes para compreender as causas da satisfação ou da insatisfação do trabalhador logo após um processo de mudança organizacional é identificar as reações do indivíduo a essa mudança na perspectiva de um contínuo, que varia entre resistência ativa em uma extremidade até cooperação total em outro extremo. Portanto, o objetivo deste estudo é compreender as implicações da mudança organizacional nos níveis de satisfação no trabalho, a partir das reações individuais à mudança. Com isso, foi realizado um survey no governo de Minas Gerais com 679 servidores para avaliar os impactos da avaliação de desempenho individual (ADI). Os dados obtidos por meio de questionários indicam que existe uma relação direta entre mudança e satisfação no setor público. Os resultados sugerem que os servidores que avaliam as mudanças de forma positiva e não resistem a elas estão mais satisfeitos com o trabalho.
\end{abstract}

Palavras-chave: resistência à mudança; qualidade de vida; satisfação no trabalho; avaliação de desempenho individual.

Cambio organizacional y satisfacción laboral: un estudio de los funcionarios públicos en el estado de Minas Gerais

Uno de los factores importantes para comprender las causas de la satisfacción o insatisfacción de los trabajadores después de un proceso de cambio organizacional es identificar las reacciones del indivi-

DOI: http://dx.doi.org/10.1590/0034-7612131034 
duo a este cambio en la perspectiva de un proceso continuo, que van desde la resistencia activa por un extremo a la plena cooperación en el otro. Por lo tanto, el objetivo de este estudio es comprender las implicaciones del cambio organizacional en los niveles de satisfacción en el trabajo, a partir de las reacciones individuales a los cambios. Con esto, un survey se desarrolló en el gobierno de Minas Gerais con 679 servidores para evaluar los impactos del programa de evaluación del desempeño individual. Los datos obtenidos a través de cuestionarios indican que existe una relación directa entre el cambio y la satisfacción en el sector público. Los servidores que evalúan los cambios de una manera positiva y no se resisten a ellos están más satisfechos con su trabajo.

Palabras clave: resistencia al cambio; la calidad de vida; satisfacción en el trabajo; la evaluación del desempeño individual.

Organizational change and work satisfaction: a study of civil servants in Minas Gerais state One of the most important factors to understand the causes of work satisfaction or dissatisfaction just after facing an organizational change process is to identify the individual reactions to this change under a continuum approach, which varies from active resistance on one ending to total cooperation on another. Therefore, the objective of this study is to understand the implications of organizational change on the levels of work satisfaction, in the light of the individual reactions to the change. A survey was developed in Minas Gerais state government in 679 public employees to evaluate the impact of the individual performance evaluation program. The data obtained from questionnaires indicates that there is a direct relationship between change and satisfaction in the public sector. Furthermore, the result suggest that the employees who evaluate the changes in a positively way and do not resist to them are more satisfied with their jobs.

KEYWORDS: resistance to change: quality of life; job satisfaction; individual performance evaluation.

\section{Introdução}

No setor público, a insatisfação do cidadão com a qualidade dos serviços prestados à população é um dos fatores que estão forçando os órgãos públicos a conduzirem mudanças no ambiente de trabalho (Osborne e Gaebler, 1994). Considerando que as instituições públicas são essencialmente instituições prestadoras de serviços, melhorar a eficácia da gestão de pessoas é fundamental para entregar serviços públicos de alta qualidade e, consequentemente, melhor atender o cidadão. No entanto, a implantação de mudanças na gestão de pessoas em organizações públicas enfrenta barreiras que muitas vezes não existem no setor privado, como o contrato de trabalho diferenciado, a falta de autonomia para recompensar e punir, e pouca preocupação com a comunicação (Rainey e Bozeman, 2000).

Apesar dessas limitações, mudanças gradativas vêm sendo observadas nas instituições públicas brasileiras e em outros países. Marconi (2003) argumenta que a gestão de recursos humanos no setor público brasileiro, que sempre se pautou pela realização de atividades operacionais e pelo comportamento reativo, vem se modernizando na medida em que os gestores públicos se conscientizam sobre a importância de se investir na formação de servidores capacitados. Mudar pessoas no contexto organizacional significa alterar a maneira como elas 
trabalham e interagem, implantando novas formas de comportamento em indivíduos e equipes de trabalho (Hersey e Blanchard, 1986; Silva e Vergara, 2000). Porém, nem sempre as mudanças são percebidas como positivas para os trabalhadores e para a organização, fazendo com que altos índices de resistência comprometam a capacidade de mudar (Lines, 2005; Chreim, 2006). Com isso, qualquer iniciativa de mudança organizacional tem alto potencial para fracassar se os trabalhadores não acreditarem que a mudança será benéfica e bem-sucedida (Seijts e Roberts, 2011).

Os processos de mudanças, tanto no setor público quanto no privado, podem ser geridos de diversas formas. Poucas são as organizações que se preocupam com os níveis de resistência à mudança investindo na comunicação, treinamento e sensibilização do funcionário (Hultman, 1995). Estas organizações reconhecem que o envolvimento do funcionário é fator de sucesso da mudança, pois os trabalhadores têm que de alguma forma mudar seu comportamento para se ajustar às novas demandas da organização. No entanto, as organizações que gerenciam os processos de mudança sem levar em conta a influência do elemento humano, além de aumentarem as chances de fracasso, comprometem o clima organizacional (Dick et al., 2006). De acordo com Lambert e Hogan (2010), os gestores que utilizam a coerção para obter adesão à mudança diminuem consideravelmente os níveis de satisfação no trabalho.

Pesquisas anteriores sugerem que há uma forte relação entre mudança organizacional e satisfação no trabalho (Bordia et al., 2010; Oreg et al., 2011). As alterações nas políticas e práticas relacionadas ao trabalho têm implicações diretas no exercício profissional dos empregados. Em tais situações, eles podem ver a mudança como uma oportunidade ou como uma ameaça para sua vida pessoal e profissional, criando sentimentos de incerteza e ambiguidade (Seijts e Rorberts, 2011) que podem afetar a percepção da satisfação no trabalho. Segundo Lambert e Hogan (2010), os funcionários que percebem as mudanças como positivas apresentam nível de satisfação com o trabalho mais elevado. Em outras pesquisas os mesmos autores encontraram que, quanto maior o conflito e a incerteza, maior é a insatisfação do empregado com o seu trabalho (Lambert et al., 2005; Hogan et al., 2006).

Portanto, o objetivo do presente trabalho é compreender como a reação dos servidores em relação à implantação da avaliação de desempenho individual (ADI) no governo de Minas Gerais influencia os níveis de satisfação no trabalho. Pretende-se contribuir para a literatura ao oferecer uma maior compreensão sobre as possíveis reações diante da mudança organizacional e como essas reações podem afetar os níveis de satisfação do trabalhador. Este estudo contribui ainda para a área de administração pública ao analisar os efeitos da mudança organizacional na satisfação no trabalho no ambiente público. Finalmente, este estudo oferece aos gestores dados empíricos sobre os efeitos da mudança organizacional na perspectiva do servidor.

\section{Referencial teórico}

Qualquer transformação de natureza estratégica, cultural, humana, estrutural ou de outra natureza que gera impacto na organização pode ser caracterizada como uma mudança organi- 
zacional (Wood et al., 1994). No entanto, Lines (2005) define mudança organizacional como uma alteração deliberadamente planejada na estrutura formal da organização, processos ou sistemas cujo objetivo é atingir as metas organizacionais. Mesmo a mudança quando planejada é capaz de gerar incertezas e turbulências no ambiente organizacional (Elias, 2009; Peccei et al., 2011).

De acordo com Piderit (2000), a reação individual à mudança organizacional é um fenômeno complexo que depende de dimensões cognitivas, emocionais e comportamentais. Enquanto a dimensão cognitiva se refere às crenças individuais em relação à mudança, a dimensão emocional está relacionada com os sentimentos que a mudança provoca. Já o aspecto comportamental é resultante da avaliação individual sobre como agir diante da mudança. Essa avaliação individual, conforme explica Piderit (2000), reflete provavelmente mais as intenções de agir futuramente do que experiências anteriores ou comportamentos passados.

Lines (2005) define a reação individual à mudança como a avaliação geral que o indivíduo faz da mudança que resulta em sua tendência psicológica de avaliá-la como favorável ou desfavorável. Nesse sentido, as crenças e emoções individuais se combinam para formar a atitude diante da mudança. Além disso, a reação individual à mudança sofre influência direta dos significados compartilhados que são construídos pelos indivíduos envolvidos na mudança (Thomas e Hardy, 2011). Esses significados nem sempre refletem visões positivas que julgam que as mudanças serão benéficas, mas muitas vezes são resultantes da forma impositiva com que a mudança foi gerida. Assim, entre as possíveis reações diante da mudança organizacional, estão a cooperação de um lado e a resistência de outro. A cooperação é caracterizada pelo engajamento e participação ativa do funcionário que contribui e facilita a mudança planejada iniciada pela organização (Kim et al., 2011).

Já a resistência é caracterizada pelo comportamento defensivo, que tem como objetivo a proteção do indivíduo dos efeitos da mudança, sejam eles reais ou imaginários (Nogueira, 1991). Hernandez e Caldas (2001) acrescentam que o comportamento de resistência objetiva a manutenção do status quo em resposta a uma pressão para modificá-lo. A mudança organizacional quase sempre está associada ao comportamento de resistência porque envolve desafios decorrentes das alterações de comportamento dos funcionários (Thomas e Hardy, 2011). Por outro lado, Piderit (2000) coloca que, ao considerar a resistência à mudança um comportamento negativo ou de desobediência, os administradores deixam de considerar preocupações válidas e importantes dos funcionários sobre as mudanças propostas.

Mesmo assim, qualquer processo de mudança organizacional planejada depende do apoio dos funcionários para obter êxito (Kim et al., 2011). Um fator decisivo para definir se o indivíduo irá cooperar ou resistir à mudança é a medida na qual ele percebe que a mudança será benéfica ou prejudicial para ele (Oreg et al., 2011). Thomas e Hardy (2011) concluem que os possíveis resultados de cooperação ou resistência dependem de como o processo de mudança é conduzido e da dinâmica de cada empresa, em um estudo realizado em uma empresa americana de telecomunicações. A mudança bem-sucedida, ou seja, aquela que resulta em novo conhecimento, inovação e colaboração dos funcionários, é resultante de práticas de comunicação baseadas no diálogo e no envolvimento relacional, onde a intervenção dos supe- 
riores é incremental e colaborativa. Por outro lado, a mudança malsucedida está relacionada com um processo imposto que resulta na simples reprodução do conhecimento existente. Esse tipo de mudança é baseado na intervenção reiterada dos superiores que usam a autoridade para obter os resultados almejados.

Para Kim e colaboradores (2011), o tempo do processo de mudança modifica as razões pelas quais os indivíduos reagem à mudança organizacional. Os resultados de um estudo realizado com 166 funcionários de um hospital americano indicam que, em um primeiro momento, o comportamento em relação à mudança depende do envolvimento formal do funcionário com a implantação da mudança e das expectativas antecipadas que o indivíduo tem em relação aos benefícios que a mudança pode trazer. Durante o processo de mudança, a participação formal do funcionário continua influenciando seu comportamento, mas as expectativas antecipadas já são conhecidas e deixam de ter efeito. Nessa fase, a qualidade das relações interpessoais e a qualidade da relação com a organização passam a influenciar a reação do funcionário.

Em geral, as atitudes positivas e fortes (colaboração ativa) são vistas como favoráveis ao sucesso da mudança, enquanto as negativas e fortes (resistência ativa) são aquelas manifestadas fortemente contra o conteúdo ou processo da mudança (Lines, 2005). Já as atitudes fracas, sejam elas positivas ou negativas, apontam que a mudança não é percebida como relevante para os membros da organização (colaboração passiva), ou ainda, que não são interpretadas como uma potencial ameaça para o funcionário (resistência passiva) (Bovey e Hede, 2001). O indivíduo pode ainda se manter neutro diante da mudança organizacional por não possuir uma opinião formada ou por, deliberadamente, decidir não reagir ao processo iniciado pela organização. Assim, as reações possíveis em relação à mudança organizacional assumem a natureza de um continuum, que vai desde a resistência ativa em um extremo até a cooperação ativa em outro extremo.

\subsection{Reações à mudança e satisfação no trabalho}

Satisfação no trabalho é a percepção que o funcionário tem de como seu trabalho preenche ou permite que sejam preenchidos certos valores individuais em relação ao trabalho (Locke, 1976). Portanto, as pesquisas sobre satisfação têm procurado identificar quais são os valores em relação ao trabalho, e como os funcionários percebem que a organização tem preenchido esses valores. Walton (1973) identificou oito fatores com que a organização deve se preocupar para promover a satisfação no trabalho: recompensa justa, segurança no trabalho (condições de trabalho), uso das capacidades humanas, possibilidade de crescimento, relacionamento interpessoal no trabalho, equidade, relevância social do trabalho e equilíbrio entre vida profissional e pessoal.

Para Hackman e Oldham (1980), a motivação do indivíduo para o trabalho depende principalmente de aspectos específicos da satisfação no trabalho, como as satisfações contextuais. As satisfações contextuais avaliam a satisfação do funcionário com a possibilidade 
de crescimento profissional, com a qualidade da supervisão, com o sistema de compensação, com o ambiente social e com a segurança no trabalho (no sentido de estabilidade). Além destes, outros pesquisadores se preocuparam em compreender as causas da satisfação no trabalho (Westley, 1979; Werther e Davis, 1983; Huse e Cummings, 1985). Mas é o modelo desenvolvido por Hackman e Oldham (1980) o apontado pela literatura sobre comportamento organizacional como um dos mais compreensivos e utilizados (Glisson e Durick, 1988; Lines, 2005).

Os níveis de satisfação no trabalho são também sensíveis aos processos de mudança organizacional. Oreg e colaboradores (2011) afirmam que uma das consequências mais citadas sobre a mudança organizacional é o impacto na satisfação no trabalho. Lines (2005) explica que a mudança impacta a satisfação no trabalho porque o indivíduo também avalia como a mudança proposta pela organização irá afetar as características no seu trabalho.

De fato, muitos dos aspectos do trabalho do funcionário, como recompensa, carreira e reconhecimento, dependem da organização e de seus líderes na figura de supervisores, gerentes, superintendentes etc. Se o funcionário acredita que a organização e seus líderes não são capazes de respeitar, defender e manter seus interesses, ele desconfiará do processo de mudança. Essa desconfiança é traduzida, consequentemente, em baixa satisfação no trabalho. Bordia e colaboradores (2010) analisaram os efeitos da mudança mal gerida em 124 funcionários de várias organizações. Eles concluem que, quando os funcionários passam por uma mudança mal gerida, eles perdem a "fé" na organização e julgam que a empresa não tem mais capacidade para manter seus interesses, fazendo com que os níveis de satisfação no trabalho caiam. Além disso, os funcionários que se recusam a ser vulneráveis e não concordam com as ações da organização, além de insatisfeitos, consideram deixar a organização.

\subsection{As mudanças na gestão de pessoas no setor público do estado de Minas Gerais}

No âmago da discussão sobre as inovações gerenciais no setor público, o governo de Minas Gerais introduziu mudanças substanciais na forma de gerenciar pessoas, visando alinhar os comportamentos, as habilidades e as atitudes dos servidores aos objetivos estratégicos de modernização do estado e da gestão das instituições públicas mineiras. A reforma administrativa denominada, em sua primeira fase, de "Choque de Gestão", iniciada em 2003, foi concebida para substituir o modelo burocrático de gestão pelo modelo de administração pública gerencial. Suas ações foram definidas com base na aplicação dos princípios do planejamento estratégico na gestão pública por resultados (Corrêa, 2007).

Tendo em vista a necessidade de estabelecer um novo padrão de gestão de pessoas e a importância dos servidores públicos para o alcance do objetivo de implantar um novo modelo de gestão pública mais eficiente, os idealizadores do Choque de Gestão promoveram mudanças na política de gestão de pessoas, com ênfase nos princípios meritocráticos e nos 
resultados. Três mudanças na política de gestão de recursos humanos foram implementadas com grande impacto na vida dos servidores: a avaliação de desempenho individual, a reestruturação das carreiras e o realinhamento de competências.

A avaliação de desempenho individual, foco deste estudo, foi instituída como um instrumento que visa proporcionar maior objetividade e imparcialidade às avaliações dos empregados, melhorar a remuneração variável dos profissionais competentes e afastar os funcionários que obtiverem repetidamente desempenho insatisfatório com o intuito de melhorar a qualidade dos serviços prestados à população (Vilhena, 2006). A ADI é realizada por uma comissão de avaliação composta pela chefia imediata do servidor, colegas de trabalho e servidores da Unidade Setorial de Recursos Humanos. Para aferir o desempenho dos servidores, foram definidos 11 critérios de avaliação: qualidade do trabalho, produtividade no trabalho, iniciativa, presteza, aproveitamento em programas de capacitação, assiduidade, pontualidade, administração do tempo e tempestividade, uso adequado dos equipamentos e instalações de serviço, aproveitamento dos recursos, racionalização de processos e capacidade de trabalho em equipe. De acordo com o percentual alcançado pelo servidor, a comissão registra o conceito obtido na avaliação como excelente, bom, regular ou insatisfatório (Minas Gerais, 2003).

Os servidores que atingem pontuações satisfatórias na ADI podem ser promovidos, podem receber o adicional de desempenho e o prêmio por produtividade. Para progredir de um grau para outro em sua carreira o servidor deverá, além de possuir o tempo de serviço e a formação necessários, obter cinco resultados satisfatórios na avaliação de desempenho individual (Silva et al., 2006). Um dos principais desafios enfrentados na implantação da ADI é a concepção de que a avaliação foi criada para punir os servidores, pois contempla a perda do cargo público caso o desempenho seja insatisfatório. Para que a demissão seja concretizada, o funcionário deve receber dois conceitos de desempenho insatisfatórios sucessivos, ou três conceitos interpolados de desempenho insatisfatório em cinco avaliações consecutivas, ou quatro conceitos interpolados de desempenho insatisfatório em 10 avaliações consecutivas. Mesmo assim, ainda é necessária a instauração de um processo administrativo garantindo ao servidor o direito ao contraditório e à ampla defesa (Vilhena et al., 2006). Portanto, a desconfiança e a apreensão dos servidores em relação à possível perda do cargo público, entre outros fatores, podem gerar sentimentos de rejeição à avaliação de desempenho individual.

A implantação da avaliação de desempenho no governo de Minas Gerais produz alterações significativas em várias dimensões do trabalho. Essas mudanças podem gerar ganhos ou prejuízos para o trabalhador e, consequentemente, influenciar sua percepção a respeito das dimensões que compõem a satisfação no trabalho (George e Jones, 2008). Portanto, esta pesquisa busca investigar como as reações dos servidores diante da implantação da avaliação de desempenho individual influenciam os níveis de satisfação no trabalho. Assim, tem-se como hipótese desta pesquisa que os servidores que apresentam reações positivas à mudança organizacional tendem a apresentar níveis de satisfação no trabalho significativamente mais elevados. 


\section{Metodologia}

Para testar a hipótese da pesquisa foi desenvolvido um survey em três Secretarias de Estado do governo de Minas Gerais, cuja mudança analisada foi a implantação da avaliação de desempenho individual. Creswell (2010) explica que o survey é caracterizado por um grande número de respondentes, ou seja, uma grande amostra para garantir a representatividade da população. Esta pesquisa é de natureza explicativa, pois as pesquisas explicativas estão preocupadas em conectar os fenômenos e entender a relação de causa e efeito. Babbie (2007) indica ainda que pesquisas explicativas procuram compreender como os fenômenos se interagem e conectam.

\subsection{População e amostra}

Esta pesquisa foi desenvolvida nas Secretarias de Estado da Educação (SEE), da Saúde, especificamente as unidades da Fundação Hospitalar do Estado de Minas Gerais (Fhemig) e na Secretaria de Estado de Planejamento e Gestão (Seplag) do estado de Minas Gerais. Essas unidades contam com o maior número de servidores em todas as categorias ocupacionais do estado e foram consideradas estratégicas na implantação das mudanças realizadas pelo governo de Minas Gerais a partir do ano de 2003. Portanto, a população deste estudo é constituída pelos 141.164 servidores que trabalham nas três secretarias de estado.

Segundo fórmula de Barnett (1991), a amostra calculada para a pesquisa, com erro amostral de 5\%, alcançou o índice mínimo de 196 indivíduos. Optou-se pela amostragem aleatória estratificada por secretaria para garantir que os servidores selecionados representassem a população de cada órgão envolvido na pesquisa. Os servidores participantes estão distribuídos da seguinte forma: 262 na Secretaria de Estado da Educação, 202 na Secretaria de Estado do Planejamento e Gestão, e 215 na Secretaria de Estado da Saúde, totalizando uma amostra de 679 respondentes.

\subsection{Instrumento de pesquisa e coleta dos dados}

O questionário padronizado é composto de três partes: 1) dados demográficos; 2) satisfação no trabalho; 3) reações à mudança organizacional. As questões referentes à satisfação no trabalho foram retiradas do modelo desenvolvido por Hackman e Oldham (1980) denominado Job Diagnostic Survey (JDS). De acordo com esse modelo, a satisfação no trabalho é formada por cinco dimensões básicas, que são: satisfação com a segurança (estabilidade), satisfação com a possibilidade de crescimento, satisfação com a remuneração, satisfação com o ambiente social e satisfação com a supervisão. Glisson e Durick (1988) explicam que o JDS é um dos mais conhecidos e utilizados na literatura sobre comportamento organizacional, obtendo bons resultados de validade e confiabilidade para diversas amostras. O construto satisfação no 
trabalho é complementado pela perspectiva de Walton (1973) em cinco diferentes dimensões: oportunidade de uso das capacidades humanas, segurança e saúde no trabalho, constitucionalismo, equilíbrio trabalho e vida, e relevância social do trabalho. Esses instrumentos foram traduzidos, testados e validados para a realidade brasileira por Moraes e Kilimnik (1989) e, posteriormente, utilizados por outros pesquisadores (Marques et al., 2008; Sant'anna et al., 2005; Borges, 2013). O alfa de Cronbach, que mede a consistência interna do construto, apresentou valores superiores a 0,7. Os itens referentes à satisfação no trabalho foram medidos por meio de uma escala de seis pontos, variando de um (totalmente insatisfeito) até seis (totalmente satisfeito).

As questões referentes às reações diante da mudança organizacional foram adaptadas do Inventário de Medida de Resistência à Mudança, desenvolvido e validado por Chaves e colaboradores (2005). De acordo com esse modelo, cinco fatores influenciam a reação individual de resistir ou cooperar com a mudança organizacional: decisão prévia, ameaça ao convívio social, consistência organizacional, resistência do grupo e experiência anterior com a mudança. Esse modelo também tem sido consistentemente testado em outros contextos com níveis de consistência interna, medido por meio do alfa de Cronbach, acima de 0,9 (Borges, 2009; Borges e Marques, 2011; Neves, 2014). Nesta pesquisa, o alfa de Cronbach para as cinco dimensões da mudança organizacional apresentou também valores superiores a 0,9 . Todas as questões sobre mudança organizacional foram obtidas por meio de escala do tipo Likert de cinco pontos, variando de discordo totalmente (1) até concordo totalmente (5).

\subsection{Análise de dados}

A análise quantitativa dos dados foi realizada em várias etapas. Primeiramente, foram identificados os casos com valores extremos, para melhor conhecer os dados e, assim, trabalhá-los de forma a garantir que as análises seguintes fossem mais precisas e confiáveis. Não foram identificados dados ausentes porque somente foram codificados os questionários que apresentaram todas as respostas completas. Em seguida, os pressupostos de normalidade e de linearidade foram avaliados. Os dados sofreram tratamentos estatísticos distintos, por meio do pacote SPSS $®$. Inicialmente, foram feitas análises baseadas em estatística descritiva. Posteriormente, foram feitas análises de correlação e regressão linear.

\section{Resultados}

\subsection{Análise descritiva dos dados}

Para analisar a qualidade de vida no trabalho dos servidores, calculou-se, primeiramente, um indicador ancorado na média das respostas para cada uma das dimensões analisadas. Definiu-se também uma variável, denominada satisfação contextual global, calculada como a 
média das médias das respostas das questões relativas às dimensões da satisfação contextual. Os dados referentes às satisfações contextuais (tabela 1) foram apresentados de acordo com os critérios desenvolvidos por Moraes e colaboradores (1995), cujos parâmetros se dividem em insatisfatório $(1,00$ a 2,99), satisfatório $(3,00$ a 3,99) e muito satisfatório $(4,00$ a 6,00). Quantos aos aspectos positivos, 84,6\% dos servidores consideram seu trabalho relevante ou muito relevante para a sociedade (relevância social do trabalho e da organização) e 93,1\% estão satisfeitos ou muito satisfeitos com o nível de integração e vida social no ambiente de trabalho (integração social). Estabilidade do emprego é uma variável muito relevante para os servidores, já que $88,7 \%$ estão satisfeitos ou muito satisfeitos com essa característica da política de gestão de pessoas do setor público. Estão satisfeitos ou muito satisfeitos com suas chefias (satisfação com a supervisão) $81,6 \%$ da população de servidores. Em síntese, a análise dos dados de forma agregada revela que $85,4 \%$ dos servidores estão satisfeitos ou muito satisfeitos com sua qualidade de vida no trabalho, com base nos indicadores avaliados.

Tabela 1

Indicadores de satisfações contextuais

\begin{tabular}{|c|c|c|c|c|c|c|c|c|}
\hline \multirow[b]{3}{*}{ Indicadores de satisfação contextuais } & \multirow[b]{3}{*}{ Média } & \multirow[b]{3}{*}{ D.P. } & \multirow{2}{*}{\multicolumn{2}{|c|}{$\begin{array}{c}\text { Insatisfatório } \\
\text { Frequência }\end{array}$}} & \multirow{2}{*}{\multicolumn{2}{|c|}{$\begin{array}{l}\text { Satisfatório } \\
\text { Frequência }\end{array}$}} & \multirow{2}{*}{\multicolumn{2}{|c|}{$\begin{array}{c}\text { Muito satisfatório } \\
\text { Frequência }\end{array}$}} \\
\hline & & & & & & & & \\
\hline & & & Abs. & Rel. (\%) & Abs. & Rel. (\%) & Abs. & Rel. (\%) \\
\hline 1. Estabilidade no emprego & 4,48 & 5,00 & 77 & 11,30 & 36 & 5,30 & 566 & 83,40 \\
\hline 2. Compensação justa e adequada & 2,50 & 2,40 & 451 & 66,40 & 132 & 19,40 & 96 & 14,10 \\
\hline $\begin{array}{l}\text { 3. Oportunidade de crescimento } \\
\text { profissional e pessoal }\end{array}$ & 2,87 & 2,87 & 361 & 53,20 & 176 & 26,40 & 139 & 20,50 \\
\hline $\begin{array}{l}\text { 4. Oportunidade de uso das } \\
\text { capacidades humanas }\end{array}$ & 3,71 & 3,80 & 151 & 22,20 & 205 & 30,20 & 323 & 47,60 \\
\hline 5. Satisfação com a supervisão & 4,02 & 4,25 & 125 & 18,40 & 107 & 15,80 & 447 & 65,80 \\
\hline 6. Integração social & 4,41 & 4,50 & 47 & 6,90 & 119 & 17,50 & 513 & 75,60 \\
\hline 7. Segurança e saúde no trabalho & 3,91 & 4,00 & 115 & 16,90 & 200 & 29,50 & 364 & 53,60 \\
\hline 8. Constitucionalismo & 3,66 & 3,75 & 174 & 25,60 & 204 & 30,00 & 301 & 44,30 \\
\hline 9. Equilíbrio trabalho e vida & 3,85 & 3,85 & 152 & 22,40 & 198 & 29,20 & 329 & 48,50 \\
\hline $\begin{array}{l}\text { 10. Relevância social do trabalho e da } \\
\text { organização }\end{array}$ & 4,00 & 4,00 & 105 & 15,50 & 158 & 23,30 & 416 & 61,30 \\
\hline 11. Satisfação contextual global & 3,74 & 3,79 & 99 & 14,60 & 311 & 45,80 & 269 & 39,60 \\
\hline
\end{tabular}

Fonte: Dados da pesquisa.

Nota: $N=679$.

Quanto aos aspectos que demandam melhoria, a tabela 1 revela que 66,4\% dos indivíduos estão insatisfeitos com o salário que recebem (compensação justa e adequada) e 
$53,2 \%$ consideram que as oportunidades de crescimento profissional e pessoal são muito limitadas nas secretarias onde trabalham. Outros quatro indicadores revelam percentual mais baixo de servidores insatisfeitos, mas que, ainda assim, demandam ações de melhoria: constitucionalismo (25,6\%), equilíbrio trabalho e vida $(22,4 \%)$, oportunidade de uso das capacidades humanas $(22,2 \%)$ e satisfação com a supervisão $(18,4 \%)$. Esse resultado parece refletir um desequilíbrio da política geral de gestão de pessoas do governo de Minas Gerais em relação às expectativas dos servidores uma vez que grande número deles $(72,4 \%)$ recebe até sete salários mínimos com poucas funções gratificadas ou comissionadas, mesmo que sua maioria apresente um elevado nível de escolaridade. Entre os servidores, $27,1 \%$ possuem nível superior completo e 32,9\% possuem pós-graduação (especialização e mestrado), somando-se assim um contingente de $60 \%$ de servidores com nível educacional elevado.

Esse resultado é também corroborado pelos dados da análise descritiva dos indicadores de satisfação contextual. As variáveis compensação justa e adequada e oportunidade de crescimento profissional e pessoal receberam notas baixas de média 2,5 e 2,87, respectivamente. Estabilidade no emprego e integração social, em contrapartida, receberam as maiores notas de média (4,48 e 4,41, respectivamente), refletindo a estabilidade que o serviço público oferece aos servidores e a percepção de boa qualidade dos relacionamentos sociais no ambiente de trabalho. O desvio padrão é baixo, indicando homogeneidade, na percepção dos servidores sobre sua qualidade de vida no trabalho.

Ao analisar a satisfação contextual global em relação aos órgãos pesquisados, obteve-se a média de 3,6 na SEE, 3,83 na Seplag e 3,82 na Fhemig. Os servidores da Seplag e da Fhemig estão satisfeitos com o contexto global de seu trabalho. Apesar da média mais baixa, os servidores da SEE também apresentam nível de satisfação contextual global adequado.

Os resultados da análise descritiva de mudança organizacional indicam que, em geral, a reação dos servidores é mais neutra em relação à implantação da $\mathrm{ADI}(\mathrm{M}=3,24$, D.P. = 1,19). Quando analisadas as cinco dimensões da reação à mudança, percebe-se que esse padrão se repete para a decisão prévia, ou seja, os trabalhadores não tinham uma opinião previamente formada sobre a avaliação de desempenho individual ( $\mathrm{M}=3,41$, D.P. = 1,09). Os resultados sugerem ainda que os servidores também estão neutros em relação à experiência anterior com a mudança organizacional $(\mathrm{M}=3,45$, D.P. $=1,29)$. Isto é, como não passaram por situações semelhantes no passado, a ausência de parâmetros de comparação fez com que, na média, os servidores permanecessem neutros em relação a essa dimensão. Os servidores responderam que resistem moderadamente à implantação da ADI no que se refere à consistência organizacional $(M=2,85$, D.P. $=1,32)$, pois julgam que os envolvidos na elaboração e implantação da avaliação de desempenho não eram os mais capacitados para a função. Finalmente, as reações positivas à implantação da ADI vieram das dimensões ambiente social $(M=4,37$, D.P. $=1,25)$ e aceitação do grupo $(M=4,36$, D.P. $=1,12)$. Isso significa que o grupo não exerceu pressão nos seus membros no sentido de resistir à mudança e que o servidor não sentiu que a implantação da ADI comprometeria o clima organizacional. 


\subsection{Análise da hipótese de pesquisa}

O resultado da análise de correlação, por meio da análise de correlação linear de Pearson, indica que existe uma correlação positiva e significativa entre a satisfação no trabalho e a reação com a implantação da $\mathrm{ADI}(r=0,381 ; p<0,01 ; \mathrm{N}=679)$. Com isso, pode-se afirmar que o pressuposto de linearidade, fundamental para detectar os desvios que influenciam na relação entre as variáveis, foi atendido. Para avaliar se a mudança organizacional, ou seja, a implantação da avaliação de desempenho individual impacta os níveis de satisfação do servidor, realizou-se a análise de regressão linear utilizando o método stepwise. Com o resultado da regressão, pode-se inferir que, nesse caso, quase $14 \%$ da variação da satisfação do servidor com o trabalho é explicada pela reação à mudança organizacional $\left(R^{2}=0,139\right)$. Esse valor pode ser pequeno se comparado com os valores aceitáveis para as pesquisas em ciências sociais aplicadas, que é em média de $30 \%$. Ressalta-se ainda que a satisfação no trabalho é um fenômeno complexo, que depende de vários fatores cognitivos. No entanto, por se tratar de um modelo simples, ou seja, explicar a variável dependente (satisfação no trabalho) a partir de somente uma variável independente (reação diante da mudança organizacional), esse resultado pode ser considerado positivo.

Finalmente, pode-se concluir que a reação do servidor em relação à implantação da avaliação de desempenho impacta os níveis de satisfação no trabalho $[F(1,677)=109,16$; $p<$ $0,001]$. Portanto, esse resultado aceita a hipótese de pesquisa ao afirmar que os servidores que apresentam reações positivas à mudança organizacional tendem a apresentar níveis de satisfação no trabalho significativamente mais elevados. Em outras palavras, quanto mais positiva for a reação do servidor com a mudança organizacional maior é a satisfação com o trabalho.

\section{Conclusões}

O objetivo deste estudo é compreender como a reação individual à mudança organizacional influencia os níveis de satisfação no trabalho. A mudança organizacional pesquisada foi a implantação do sistema de avaliação de desempenho individual no estado de Minas Gerais. Portanto, a hipótese colocada para pesquisa afirma que as reações positivas dos servidores à implantação da avaliação de desempenho individual resultam em níveis de satisfação no trabalho significativamente mais elevados. Em contrapartida, a resistência à mudança organizacional resultaria em índices inferiores de satisfação no trabalho. Com a aceitação da hipótese de pesquisa, foi possível também avaliar a percepção dos servidores em relação à mudança e compreender melhor os níveis de satisfação no trabalho a partir das dimensões estudadas.

\subsection{Implicações}

Os resultados desta pesquisa oferecem algumas implicações teóricas e práticas. Do ponto de vista teórico, este trabalho contribui para a compreensão da mudança organizacional no 
contexto público. Embora os gestores convivam com peculiaridades inerentes à administração pública, pode-se inferir que, a exemplo do setor privado, os processos de mudança organizacional também influenciam a satisfação no trabalho, dando suporte aos achados de Lines (1995), Bordia e colaboradores (2010) e Oreg e colaboradores (2011).

Além disso, os dados deste estudo exemplificam a perspectiva defendida por alguns autores de que a reação individual à mudança organizacional é um fenômeno complexo (Piderit, 2000). A reação individual à mudança organizacional depende da avaliação psicológica que o funcionário realiza em função de seus valores, crenças e emoções. De fato, os resultados indicam que as reações dos servidores diferem de acordo com a avaliação que realizam de certos aspectos da mudança. Eles podem cooperar ou resistir por motivos diferentes. Nesse caso, os servidores cooperam com a implantação da avaliação individual de desempenho porque eles julgam que a mudança não afetou o clima organizacional, especificamente seu relacionamento com os colegas e com os superiores. Da mesma forma, o grupo apresentou uma percepção positiva julgando que as mudanças não seriam uma ameaça. A coerência entre a percepção do indivíduo e a pressão que o grupo exerce sobre ele pode ser resultado dos significados que são construídos e compartilhados pelos membros da organização e que influenciam a reação do indivíduo à mudança, conforme afirmam Thomas e Hardy (2011).

No entanto, os funcionários permanecem neutros quando perguntados sobre outros aspectos da implantação da avaliação individual de desempenho, como em relação à reação prévia a ADI e à experiência anterior com um processo de mudança semelhante. No entanto, somente em relação à consistência organizacional os servidores resistem porque julgam que a organização e os profissionais envolvidos na concepção e implantação da avaliação de desempenho não são os mais capacitados para a tarefa.

Esses resultados trazem também implicações práticas. O fato de os servidores perceberem que a instituição não é capaz de desenvolver e implantar a avaliação de desempenho pode ter relação com a confiança que o servidor deposita na organização e em seus líderes (Bordia et al., 2010). Especialmente no contexto brasileiro, os gestores desempenham um papel fundamental para manter a confiança do servidor na organização e reduzir o cinismo organizacional, presente em processos de mudança organizacional. Portanto, esse dado pode ser um indicativo de que houve falha no processo de comunicação e que a administração pública não foi capaz de convencer seus funcionários da sua competência para desenvolver e implantar a mudança.

Além de oferecer para os gestores dados sobre as fontes de resistência e cooperação com a avaliação de desempenho, este trabalho permite também que os gestores conheçam as causas da satisfação e da insatisfação dos servidores. Os dados indicam que a maioria dos servidores está muito satisfeita, principalmente, com a estabilidade no emprego, seguida pela integração social, supervisão, relevância social do trabalho e condições de trabalho (segurança e saúde). Por outro lado, a maioria dos respondentes está insatisfeita com o sistema de recompensa e com a possibilidade de crescimento profissional. Tanto o sistema público estadual de recompensa (salário e benefícios) quanto o plano de carreira são fontes de insatisfação recorrentes no funcionalismo público. Cabe, portanto, à administração pública, em geral, em- 
preender esforços para modernizar a gestão no sentido de oferecer carreiras e recompensas mais atrativas.

Finalmente, os resultados sugerem que uma parte da satisfação no trabalho é influenciada pela implantação do sistema de avaliação individual de desempenho. Ou seja, a forma como a mudança é realizada influencia diretamente os níveis de satisfação no trabalho. Quanto mais os gestores forem realistas em relação à avaliação de desempenho, maiores serão as chances de os servidores construírem uma percepção positiva e reagirem de forma a cooperar com a mudança. Lines (2005) chama a atenção para as fases iniciais do processo de mudança e enfatiza a necessidade de os gerentes lidarem com as emoções no ambiente de trabalho. Contudo, não somente em relação à avaliação de desempenho, mas também em relação às mudanças planejadas, a administração pública precisa preocupar-se com o envolvimento e as emoções no trabalho, treinando os gestores, promovendo workshops, ouvindo sugestões e discutindo as mudanças com os servidores que sofrerão diretamente seu impacto.

\subsection{Limitações}

Esta pesquisa, como toda pesquisa científica, apresenta algumas limitações. As limitações metodológicas incluem a amostragem, análises estatísticas, entre outras. Da estratégia de coleta de dados decorre a impossibilidade de generalizar os resultados para outros estados do Brasil que implantaram a avaliação de desempenho. Pesquisas futuras podem realizar surveys incluindo os estados de São Paulo, Pernambuco, Espírito Santo etc. para identificar se os resultados são consistentes. Embora as exigências estatísticas em relação à amostragem tenham sido atendidas, o quanto a amostra representa as três secretarias de estado e, principalmente, o quanto as secretarias representam o funcionalismo público do estado de Minas Gerais ainda podem ser questionados. Finalmente, ao utilizar o nível de significância estatística, reconhecese a probabilidade de $5 \%$ de chance de cometer o erro tipo I. Outras questões como variância do método comum são incluídas também com uma limitação do método.

Finalmente, outro tipo de limitação decorre da abordagem teórica utilizada. Esta pesquisa reconhece que as reações à mudança organizacional são resultado de avaliações psicológicas que o indivíduo realiza sobre o processo de mudança. Essas reações podem ser cooperativas ou resistentes em maior ou menor grau. No entanto, Piderit (2000) chama a atenção para a ambivalência das reações individuais à mudança. Em outras palavras, o indivíduo acredita que a mudança é ruim para ele e para a organização, mas não quer enfrentar todas as consequências advindas de um comportamento resistente. Por isso, embora o funcionário não acredite na mudança, ele age de forma indiferente ou até colaborativa em algumas situações. Pesquisas futuras podem aprofundar a compreensão sobre a reação à mudança organizacional analisando as três dimensões propostas por Piderit (2000), com o objetivo de captar possíveis ambivalências.

Os resultados desta pesquisa evidenciam a necessidade do envolvimento (psicológico e formal) do servidor no processo de mudança organizacional, pois a percepção negativa pode 
desencadear comportamentos resistentes que, consequentemente, comprometem a satisfação no trabalho. Especificamente para o governo de Minas Gerais, este trabalho destaca a importância de se adotarem estratégias mais eficazes de implantação de mudanças organizacionais que promovam o envolvimento dos servidores, minimizem o comportamento resistente e melhorem os níveis de satisfação no trabalho.

\section{Referências}

BABBIE, Earl R. The pactice of social research. California: Wadsowrth, Cengage Learning, 2007.

BARNETT, Vic. Sample survey: principles and methods. Londres: Arnold, 1991.

BORDIA, Prashant et al. Haunted by the past: effect of poor change management on employee attitudes and turnover. Group \& Organization Management, v. 20, n. 10, p. 1-32, 2010.

BORGES, Renata. Are public officials really less satisfied than private sector workers? A comparative study in Brazil. Rev. Adm. Pública, v. 47, n. 6, p. 1477-1496, nov./dez. 2013.

BORGES, Renata. Organizational change implementation and the role of human resource practices: a Brazilian case study. Brazilian Business Review, v. 6, n. 3, p. 284-295, 2009.

BORGES, Renata S. G.; MARQUES, Antônio L. Gestão da mudança: uma alternativa para a avaliação do impacto da mudança organizacional. Revista de Administração Faces Journal, v. 10, n. 1, p. 95-113, 2011.

BOVEY, Wayne H.; HEDE, A. Resistance to organisational change: the role of defense mechanisms. Journal of Managerial Psychology, v. 16, n. 7, p. 534-548, 2001.

CHAVES, Rosana C.; MARQUES, Antônio L.; DIAS, Alexandre T. Validando um instrumento de medida de resistência à mudança. In: ENANPAD, 19., 2005, Brasília. Anais... Brasília: Anpad, 2005. p. 1-16.

CHREIM, Samia. Managerial frames and institutional discourses of change: employee appropriation and resistance. Organization Studies, v. 27, n. 9, p. 1261-1287, 2006.

CORRÊA, Izabela M. Planejamento estratégico e gestão pública por resultados no processo de reforma administrativa do estado de Minas Gerais. Rev. Adm. Pública, v. 41, n. 3, p. 487-504, maio/jun. 2007.

CRESWELL, John W. Projeto de pesquisa: métodos qualitativo, quantitativo e misto. 3. ed. Porto Alegre: Artmed, 2010.

DICK, Rolf; ULLRICH, Johannes; TISSINGTON, Patrick A. Working under a black cloud: how to sustain organizational identification after a merger. British Journal of Management, v. 17, n. S1, p. 69-79, 2006.

ELIAS, Steven M. Employees' commitment in times of change: assessing the importance of attitudes towards organizational change. Journal of Management, v. 35, n. 1, p. 37-55, 2009. 
GEORGE, Jennifer M.; JONES, Gareth R. Understanding and managing organizational behavior. 5. ed. Upper Saddle River, NJ: Pearson Prentice Hall, 2008.

GLISSON, Charles; DURICK, Mark. Predictors of job satisfaction and organizational commitment. Administrative Science Quarterly, v. 33, n. 1, p. 61-81, 1988.

HACKMAN, Richard J.; OLDHAM, Greg R. Work redesign. Reading, MA: Addison-Wesley, 1980.

HAIR, Joseph F. et al. Análise multivariada de dados. 5. ed. Porto Alegre: Bookman, 2005.

HERNANDEZ, José M. C.; CALDAS, Miguel P. Resistência à mudança: uma revisão crítica. Revista de Administração de Empresas, v. 41, n. 2, p. 31-45, 2001.

HERSEY, Paul; BLANCHARD, Kenneth H. Psicologia para administradores: a teoria e as técnicas da liderança situacional. São Paulo: EPU, 1986.

HOGAN, Nancy L. et al. The impact of occupational stressors on correctional staff organizational commitment: a preliminary study. Journal of Contemporary Criminal Justice, v. 22, n. 1, p. 33-62, 2006.

HULTMAN, Kenneth E. Scaling the wall of resistance. Training and Development, v. 49, n. 10, p. 15-18, 1995.

HUSE, Edgar F.; CUMMINGS, Thomas G. Organization development and change. 3. ed. St. Paul, Minn: West, 1985.

KIM, Tai G.; HORNUNG, Severin; ROUSSEAU, Denise M. Change-supportive employee behavior: antecedents and the moderating role of time. Journal of Management, v. 37, n. 6, p. 1664-1693, 2011.

LAMBERT, Eric G.; HOGAN, Nancy L. Wanting change: the relationship of perceptions of organizational innovation with correctional staff job stress, job satisfaction, and organizational commitment. Criminal Justice Police Review, v. 21, n. 2, p. 160-184, 2010.

LAMBERT, Eric G. et al. Here today, gone tomorrow, back again the next day: absenteeism and its antecedents among federal correctional staff. Journal of Criminal Justice, v. 33, n. 2, p. 165-175, 2005.

LINES, Rune. The structure and function of attitudes toward organizational change. Human Resource Development Review, v. 4, n. 1, p. 8-32, 2005.

LOCKE, Edwin A. The nature and causes of job satisfaction. In: DUNETTE, Marvin D. Handbook of industrial and organizational psychology. Chicago: Rand McNaly, 1976. p. 1297-1349.

MALHOTRA, Naresh K. Pesquisa de marketing: uma orientação aplicada. 4. ed. Porto Alegre: Bookman, 2001.

MARCONI, Nelson. A evolução do perfil da força de trabalho e das remunerações nos setores público e privado ao longo da década de 1990. Revista do Serviço Público, v. 54, n. 1, p. 9-45, 2003.

MARQUES, Antônio L.; ADORNO, Ronara D.; BORGES, Renata S. G. A LDB/96 e qualidade de vida no trabalho: com a palavra os docentes da rede pública de Belo Horizonte. Revista de Ciências da Administração, v. 10, n. 20, p. 70-92, 2008. 
MINAS GERAIS. Lei Complementar nº 71, de 30 de julho de 2003. Institui a avaliação periódica de desempenho individual, disciplina a perda de cargo público e de função pública por insuficiência de desempenho do servidor público estável e do detentor de função pública na Administração Pública Direta, Autárquica e Fundacional do Poder Executivo e dá outras providências. Minas Gerais, Belo Horizonte, 31 jul. 2003.

MORAES, Lúcio F. R.; KILIMNIK, Zélia M. A qualidade de vida no trabalho burocrático automatizado. Belo Horizonte: Cepead/UFMG, 1989.

MORAES, Lúcio F. R. et al. Comprometimento organizacional, qualidade de vida e stress no trabalho: uma abordagem de diagnóstico comparativo. Revista de Administração Contemporânea, Rio de Janeiro, v. 1, n. 9, p. 170-185, 1995.

NEVES, Lívia A. Resistência à mudança no processo de fusão. Dissertação (mestrado em administração) - Centro de Pós-Graduação e Pesquisas em Administração, Universidade Federal de Minas Gerais, Belo Horizonte, 2014.

NOGUEIRA, Márcia F. L. Mudança organizacional: causas e formas de resistência, um estudo da Universidade Federal do Ceará. Dissertação (mestrado em administração) - Centro de Pós-Graduação e Pesquisas em Administração, Universidade Federal de Minas Gerais, Belo Horizonte, 1991.

OREG, Shaul; VAKOLA, Maria; ARMENAKIS, Achilles. Change recipients' reactions to organizational change: a 60-year review of quatitative studies. The Journal of Applied Behavioral Science, v. 47, n. 4, p. 461-524, 2011.

OSBORNE, David; GAEBLER, Ted. Reinventando o governo: como o governo empreendedor está transformando o setor público. Brasília: MH Comunicação, 1994.

PECCEI, Ricardo; GIANGRECO, Antonio; SEBASTIANO, Antonio. The role of organizational commitment in the analysis of resistance do change: co-predictor and moderator effects. Personnel Review, v. 40, n. 2, p. 185-204, 2011.

PIDERIT, Sandy K. Rethinking resistance and recognizing ambivalence: a multidimensional view of attitudes toward an organizational change. Academy of Management Review, v. 25, n. 4, p. 783794, 2000.

RAINEY, Hal G.; BOZEMAN, Barry. Comparing public and private organizations: empirical research and the power of the a priori. Journal of Public Administration Research and Theory, v. 10, n. 2, p. 447-469, 2000.

SANT'ANNA, Anderson S.; MORAES, Lúcio F. R.; KILIMNIK, Zélia M. Competências individuais, modernidade organizacional e satisfação no trabalho: um estudo de diagnóstico comparativo. Revista de Administração, v. 4, n. 1, p. 1-23, 2005.

SEIJTS, Gerard H.; ROBERTS, Michael. The impact of employee perceptions on change in a municipal government. Leadership \& Organization Development Journal, v. 32, n. 2, p. 190-213, 2011.

SILVA, Jomara; BERNARDI, Mônica; JORGE, Maria A. Avaliação de desempenho individual. In: VILHENA, Renata et al. (Org.). O choque de gestão em Minas Gerais: políticas da gestão pública para o desenvolvimento. Belo Horizonte: Ed. UFMG, 2006. 
SILVA, José R. G.; VERGARA, Sylvia C. O significado da mudança: as percepções dos funcionários de uma empresa brasileira diante da expectativa de privatização. Rev. Adm. Pública, v. 34, n. 1, p. 79-99, 2000.

THOMAS, Robyn; HARDY, Leisa D. S. Managing organizational change: negotiating meaning and power-resistance relations. Organization Science, v. 22, n. 1, p. 22-41, 2011.

VILHENA, Renata. Rumo à segunda geração do choque de gestão. In: VILHENA, Renata et al. (Org.). O choque de gestão em Minas Gerais: políticas da gestão pública para o desenvolvimento. Belo Horizonte: Editora UFMG, 2006. p. 351-356.

WALTON, Richard E. Quality of working life: what is it? Sloan Management Review, v. 15, n. 1, p. 11-21, 1973.

WERTHER, William B.; DAVIS, Kingsley. Administração de pessoal e recursos humanos. São Paulo: McGraw-Hill do Brasil, 1983.

WESTLEY, William A. Problems and solutions in the quality of working life. Human Relations, v. 32, n. 2, p. 113-123, 1979.

WOOD, Thomas JR.; CURADO, Isabela B.; CAMPOS, Humberto M. Vencendo a crise: mudança organizacional na Rhodia Farma. Revista de Administração de Empresas, v. 34, n. 5, p. 67-79, 1994.

Antônio Luiz Marques é professor titular da Faculdade Novos Horizontes e coordenador do curso de mestrado em administração. E-mail: antonio.marques@unihorizontes.br.

Renata Borges é professora da Faculdade de Ciências Econômicas (Face) da Universidade Federal de Minas Gerais (UFMG) e coordenadora do Núcleo de Estudos em Gestão Organizacional e Tecnologias Gerenciais da UFMG. E-mail: renatasg@face.ufmg.br.

Isabella do Couto Reis é mestre em administração pela Universidade Federal de Minas Gerais (UFMG) e pesquisadora do Núcleo de Estudos em Gestão Organizacional e Tecnologias Gerenciais da UFMG e do Núcleo de Estudos Organizacionais Críticos e Transdisciplinares da UFMG. E-mail: isabellacoutoreis@ gmail.com. 